\title{
Normatização dos Equipamentos e Técnicas para Realização de Exames de Teste de Inclinação Ortostática (tilt table test)
}

\author{
Coordenador \\ Jorge Ilha Guimaraes \\ Editores
}

Eduardo Sosa (SP); Fábio Sândoli de Brito (SP); Ivan Maia (RJ); José Carlos Pachón Mateos (SP); Júlio Gizzi (SP); Márcio Fagundes (RJ); Martino Martinelli Filho(SP); Roberto Costa(SP)

\section{Participantes}

André d'Ávila (SP); Adalberto Lorga Filho(SP); Anísio Pedrosa (SP); Álvaro Barros da Costa (RN); Ayrton Peres (DF); César Grupi (SP);

Cláudio Cirenza(SP); Dalmo Moreira(SP);

Dário Sobral (PE); Denise Hachul(SP);

Eduardo D'Andréa(RJ); Epotamenides M. Good God(MG); Guilherme Fenelon(SP); Gustavo GlotzLima(RS); Hélio Brito (MG); José Carlos Moura Jorge (PR); José Carlos de Andrade (SP); José Carlos Ribeiro(RJ); João Pimenta (SP); José Tarcísio de Vasconcelos (SP); Leandro Zimerman (RS); Márcio Fagundes (RJ); Márcio Figueiredo(SP); Ney Valente(SP);

Paulo Medeiros (SP); Reynaldo Castro Miranda(MG);

Ricardo Kunyioshi(ES); Roberto Sá (RJ);

Sérgio G. Rassi (GO); Sérgio Siqueira (SP);

Silas Galvão (SP); Silvana Nishioka (SP);

Tereza Grillo (MG); Thiago da Rocha Rodrigues (MG); Washington Maciel (RJ)

\section{Definição}

O teste de inclinação ortostática (TI) ou tilt table test é um método provocativo, utilizado para avaliação da susceptibilidade à síncope neurocardiogênica ou vasovagal. $\mathrm{O}$ estresse postural, induzido pela inclinação passiva do paciente do decúbito dorsal horizontal para a posição ortostática, reproduz nesse indivíduo hipotensão e bradicardia neuromediadas, responsáveis por eventos sincopais.

\section{Recursos Hospitalares}

Deve ser realizado em ambiente hospitalar e o laboratório deve ser silencioso, com iluminação regulável e temperatura amena.

\section{Equipamento Necessário}

Maca basculante, com capacidade de inclinação de -20 graus (posição de Trendelenburg) até 70 graus ortostáticos, com apoio para os pés e cintos de segurança; monitor e registrador do eletrocardiograma contínuo; monitorização de pressão arterial, para o que é preferível monitor de pressão arterial batimento a batimento, não invasivo; no caso de monitor intermitente, as medidas devem ser feitas com a maior freqüência possível; equipamento de reanimação cardiorrespiratória, em caso de necessidade de recuperação do paciente após indução de síncope; monitorização da oximetria periférica é aconselhável; bomba de infusão.

\section{Especificações Técnicas do Procedimento}

Em não havendo um teste padrão ouro, o tempo de repouso, o tempo de inclinação, o ângulo de inclinação e a sensibilização do teste por drogas podem variar entre diferentes protocolos. De uma maneira geral, sugere-se que:

- sua realização pode ocorrer no período matutino ou vespertino;

- estudos repetidos, com objetivo de avaliação de eficácia terapêutica, devem serrealizados nomesmo período do dia;

- o paciente deve permanecer em jejum oral por, pelo menos, 6h para sólidos e $4 \mathrm{~h}$ para líquidos e estar adequadamente hidratado;

- não é recomendada a permanência de familiares no laboratório, sendo que, em caso de crianças pequenas ou pacientes dependentes, deve ser ponderada a presença de apenas um acompanhante;

- o período de repouso deve ser de, pelo menos, 20 minutos em decúbito dorsal horizontal, sendo que a elevação passiva da maca é feita em 10 a 15 segundos;

- a inclinação pode variar entre $60^{\circ}$ e $70^{\circ}$;

- exposição à postura ortostática deve ser feita entre 40 e 45 minutos, para o teste passivo para adultos e $20 \mathrm{mi}$ nutos, para crianças.

Para sensibilização por drogas, pode-se usar:

- isoproterenol: dose de 1 a $2 \mathrm{mcg} / \mathrm{min}$, em infusão endovenosa por bomba de infusão, na diluição de uma ampola de isoproterenol 1:5000 para $100 \mathrm{ml}$ de soro glicosado ou fisiológico, realizada a partir dos últimos 5 minutos de repouso em decúbito horizontal; tempo de inclinação de, no máximo, 20min;

- dinitrato de isossorbida: dose de 1,25mg via sublingual, administrada nos últimos $5 \mathrm{~min}$ de repouso em decúbito horizontal, ou durante o teste passivo, depois de completados os primeiros $20 \mathrm{~min}$ de exposição à postura ortostática; tempo de inclinação entre 15 a $20 \mathrm{~min}$.

\section{Recursos Humanos}

É necessária a presença de um médico especializado durante todo o procedimento; é necessária a presença de técnico ou auxiliar de enfermagem capacitado para atendimento de emergência.

\section{Relatório Mínimo}

- Identificação do paciente: nome, idade.

- Relato sobre uso de fármacos que podem interferir no resultado e na sua interpretação.

- Descrição do procedimento: protocolo simples ou sensibilizado com fármacos.

- Descrição dos sintomas relatados pelo paciente durante o procedimento.

- Gráfico contendo os valores da pressão arterial e freqüência cardíaca durante o procedimento.

- Conclusão: se o teste foi positivo, definir o padrão de resposta hemodinâmica. 